Vol II. No. 2, Maret 2018, hlm. 157 - 165

Available online at www.jurnal.una.ac.id/indeks/jmp

\title{
STRATEGI PENERAPAN MODEL PEMBELAJARAN KOOPERATIF TIPE JIGSAW PADA MATA KULIAH METODE NUMERIK
}

\author{
Nur Qomariyah Nawafilah", ${ }^{1}$ Masruroh $^{2}$ \\ Universitas Islam Lamongan \\ e-mail: nq.nawafil@gmail.com
}

\begin{abstract}
The aim of this research is to know the application strategy of jigsaw type cooperative learning model in university so that improving the students' activities and learning outcomes on numerical method lecture. The study used a type of class action research in two cycles. Each cycle is done in two meetings. Subjects of this research are the 24 students of class $3 C$ in Informatics Engineering department of Universitas Islam Lamongan.The result showed that application of jigsaw type cooperative learning in university needs well prepared and strategies. The strategies include material selection which appropriate with jigsaw type, formation of heterogeneous expert groups, understanding of student characteristics, mentoring during discussions in origin and expert groups, and additional learning resources. The application of correct strategies in jigsaw type cooperative learning improving the students' activities and learning outcomes.
\end{abstract}

Keywords: Strategy, Cooperative Learning of Jigsaw Type

\begin{abstract}
Abstrak
Penelitian ini bertujuan untuk mengetahui strategi penerapan model pembelajaran kooperatif tipe jigsaw di universitas sehingga dapat meningkatkan aktivitas dan hasil belajar mahasiswa pada mata kuliah metode numerik. Penelitian menggunakan jenis penelitian tindakan kelasdengan 2 siklus. Setiap siklus dilakukan dalam dua kali pertemuan. Subjek penelitian adalah mahasiswa kelas 3C Teknik Informatika Universitas Islam Lamongan yang berjumlah 24. Hasil penelitian menunjukkan bahwa penerapan pembelajaran kooperatif tipe jigsaw di universitas memerlukan persiapan dan strategi yang matang. Strategi-strategi yang dilakukan antara lain pemilihan materi yang cocok untuk model jigsaw, pembentukan kelompok asal yang homogen agar terbentuk kelompok ahli yang heterogen, pemahaman karakteristik mahasiswa, pendampingan selama proses diskusi di kelompok asal dan ahli, dan tambahan sumber belajar. Penerapan strategi pembelajaran kooperatif tipe jigsaw yang tepat dapat meningkatkan aktivitas dan hasil belajar siswa.
\end{abstract}

Kata Kunci: Strategi,Pembelajaran Kooperatif Tipe Jigsaw

Proses belajar mengajar akan dapat berjalan dengan lancar, kondusif, interaktif, dan dapat mencapai tujuan pembelajaran apabila dilandasi oleh strategi pembelajaran yang baik dan benar. Dengan strategi yang matang diharapkan suasana pembelajaran terasa menyenangkan 
Vol II. No. 2, Maret 2018, hlm. 157 - 165

Available online at www.jurnal.una.ac.id/indeks/jmp

sehingga siswa akan merasa tertarik dan dapat memperkuat kemampuan kognitif, afektif dan psikomotor serta tujuan pembelajaran dapat tercapai. Matematika merupakan suatu ilmu yang berhubungan atau menelaah bentuk-bentuk atau struktur-struktur yang abstrak danhubungan-hubungan di antara satu dengan yang lain. Untuk dapat memahami strukturstruktur serta hubungan-hubungan, tentu saja diperlukan pemahaman tentang konsep-konsep yang terdapat di dalam matematika (Hudojo, 2005: 103). Karena matematika ini mencakup materi yang cukup luas, maka untuk menyelesaikan target ketuntasan belajar siswa perlu perencanaan strategi pembelajaran yang matang.

Tipe jigsaw merupakan salah satu model pembelajaran kooperatif yang menitikberatkan pada kerjasama siswa dalam kelompok kecil. Slavin (2014: 13) menyatakan bahwa garis besar dari pelaksanaan model pembelajaran kooperatif adalah memberi kesempatan siswa untuk berdiskusi, saling bertukar pendapat, presentasi, dan mengoreksi pekerjaan teman satu dengan lainnya. Pembelajaran tipe jigsaw memberikan kesempatan siswa untuk bekerjasama, terbuka, dan bertanggungjawab atas tugas dalam menyelesaikan masalah (Widayanti, 2017). Selain itu Solihatin dan Raharjo (2008) juga mengungkapkan bahwa dalam model pembelajaran jigsaw siswa diatur menjadi kelompok-kelompok. Terdapat dua macam kelompok yaitu kelompok asal dan kelompok ahli.
Melalui langkah-langkah pembelajaran jigsaw siswa dituntut untuk kerja sama, kerja keras, bertanggungjawab, jujur dan lainnya. Berdasarkan paparan mengenai pembelajaran tipe jigsaw dapat dikatakan bahwa tipe satu ini dapat melatih siswa mempunyai keberanian untuk bertanya dan mengemukakan pendapat, sehingga harapannya dapat meningkatkan keefektifan proses pembelajaran. Beberapa kelebihan model pembelajaran kooperatif tipe jigsaw menurut Fathurrohman (2015), yakni sebagai berikut: (1) Siswa dapat bekerjasama dengan sesama siswa dalam suasana gotong royong, (2) Siswa mempunyai banyak kesempatan untuk mengolah informasi dan meningkatkan keterampilan berkomunikasi, (2) Bertanggung jawab atas penguasaan materi dan mampu mengajarkan materi tersebut kepada anggota lain dalam kelompoknya, dan (4) meningkatkan rasa tanggung jawab siswa terhadap pembelajarannya sendiri dan juga pembelajaran orang lain.

Berdasarkan hasil belajar mahasiswa kelas 3C Teknik Informatka Universitas Islam Lamongan pada mata kuliah Metode Numerik menunjukkan bahwa hasil kuis I kurang memuaskan. Diperoleh ratarata kelas yaitu 58,44. Hasil kuis I ini menggambarkan sejauh mana penguasaan materi mahasiswa pada mata kuliah metode numerik yang disampaikan oleh dosen. Berdasarkan hasil wawancara pada kegiatan observasi awal, mayoritas mahasiswa mengalami kesulitan dalam hal 
Vol II. No. 2, Maret 2018, hlm. 157 - 165

Available online at www.jurnal.una.ac.id/indeks/jmp

ketelitian saat menyelesaikan masalah. Hal ini dikarenakan menurut mereka metode-metode yang mereka jumpai tersebut prosesnya cukup panjang dan merupakan hal yang baru bagi mereka selaku mahasiswa Teknik Informatika.

Tujuan dari penelitian ini adalah untuk mengetahui strategi apa saja yang perlu disiapkan dalam menerapkan model pembelajaran kooperatif tipe jigsaw pada mata kuliah Metode Numerik sehingga dapat meningkatkan hasil belajar mahasiswa.

\section{METODE}

Jenis penelitian ini termasuk penelitian tindakan kelas (PTK) yang terdiri dari 2 siklus. Tujuan PTK adalah untuk memperbaiki mutu pembelajaran di kelas. Penelitian ini dilakukan di Universitas Islam Lamongan pada semester ganjil tahun ajaran 2016/2017. Subjek penelitian adalah mahasiswa yang menempuh mata kuliah Metode Numerikkelas 3C Teknik Informatika. Penelitian dilakukan bersama antara peneliti 1 dan peneliti 2. Penelitian ini dilakukan untuk mengambil data: (1) hasil pengamatan selama pembelajaran, dan (2) nilai maha-siswa. Pengamatan dilakukan untuk mengetahui keterlaksanaan pem-belajaran dengan menggunakan model pembelajaran kooperatif tipe jigsaw.

Pendekatan yang digunakan untuk analisis data keterlaksanaan pembelajaran yakni pendekatan kualitatif deskriptif. Analisis dilakukan dengan cara merefleksi hasil observasi dan hasil tes belajar mahasiswa. Untuk mengukur keefektifan penerapan model pembelajaran jigsaw dilakukan observasi terhadap jalannya diskusi kelompok ahli dan asal. Martinis, Yamin (2013:91) menjelaskan bahwa pelaksanaan pembelajaran menggunakan metode kooperatif tipe jigsaw akan efektif apabila: terdapat kerjasama, tanggungjawab anggota kelompok, saling percaya, dan semua anggota aktif. Berdasarkan aspekaspek keefektifan pelaksanaan model jigsaw tersebut, maka indikatorindikator yang ada pada lembar observasi meliputi: 1) mendengarkan penjelasan anggota lain, 2) mencatat hasil diskusi, 3) mengemukakan pendapat, 4) memberi respon pendapat/ sanggahan/ kritik anggota lain, 5) tidak mendominasi diskusi, 6) berdiskusi dengan baik. Masingmasing indikator diberi skor dari rentang 1 sampai 5. Skor maksimal 30. Penghitungan skor yang diperoleh menggunakan rumus:

$$
\text { skor }=\frac{\text { skor yang diperoleh }}{\text { skor maksimal }} \times 100
$$

Kriteria keaktifan mahasiswa dapat dilihat pada Tabel 1 berikut.

Tabel 1. Kriteria Keaktifan Mahasiswa

\begin{tabular}{cc}
\hline Rentang skor & Kriteria Keaktifan \\
\hline$>80$ & Sangat aktif \\
$70-80$ & Aktif \\
$60-70$ & Kurang aktif \\
$<60$ & Tidak aktif \\
\hline \multicolumn{2}{c}{ Hasil skor keaktifan mahasiswa } \\
dikomparasi dengan hasil belajar \\
mahasiswa dan diskripsi tiap siklus
\end{tabular}


Vol II. No. 2, Maret 2018, hlm. 157 - 165

Available online at www.jurnal.una.ac.id/indeks/jmp

menjadi simpulan terhadap strategi penerapan model pembelajaran kooperatif tipe jigsaw pada mata kuliah Metode Numerik. Analisis terhadap hasil belajar sendiri dapat dilakukan dengan memberikan test di akhir siklus. Nilai minimal keberhasilan tindakan terhadap hasil belajar adalah 70. Tindakan dinyatakan berhasil apabila 70\% mahasiswa telah mencapai atau melampaui 70 .

\section{HASIL DAN PEMBAHASAN}

\section{Hasil Penelitian}

Penerapan model pembelajaran kooperatif tipe jigsaw dilaksanakan dalam dua siklus, dengan tiap siklus dilaksanakan dalam dua kali pertemuan. Alokasi waktu untuk masing-masing pertemuan yakni $3 \mathrm{x}$ 50 menit. Proses pelaksanaan setiap siklus terdiri dari: 1) perencanaan, 2) pelaksanaan pembelajaran, 3) pelaksanaan observasi atau pemantauan, dan 4) refleksi (Rochiati, 2008:66). Perencanaan pada siklus 1 merupakan tindak lanjut dari hasil analisis pra tindakan. Sedangkan perencanaan pada siklus selanjutnya merupakan perbaikan atas pelaksanaan pembelajaran pada siklus sebelumnya.

\section{Hasil Siklus 1}

Perencanaan pembelajaran pada siklus satu adalah menyusun perangkat pembelajaran dan instrumen penelitian. Perangkat pembelajaran terdiri atasRPP, lembar kerja mahasiswa, bahan ajar, dan instrumen test. Untuk pembagian

kelompok asal dan kelompok ahli pada siklus 1 diserahkan sepenuhnya kepada mahasiswa. Mereka membagi kelas menjadi 6 kelompok asal dengan masing-masing kelompok terdiri atas 4mahasiswa. Masingmasing anggota bergabung dalam kelompok ahli yang terdiri atas 4 kelompok dengan tiap kelompok ahli terdiri atas 6 mahasiswa. Adapun secara garis besar langkah-langkah pembelajaran model pembelajaran jigsaw yang dilakukan oleh dosen digambarkan seperti berikut.

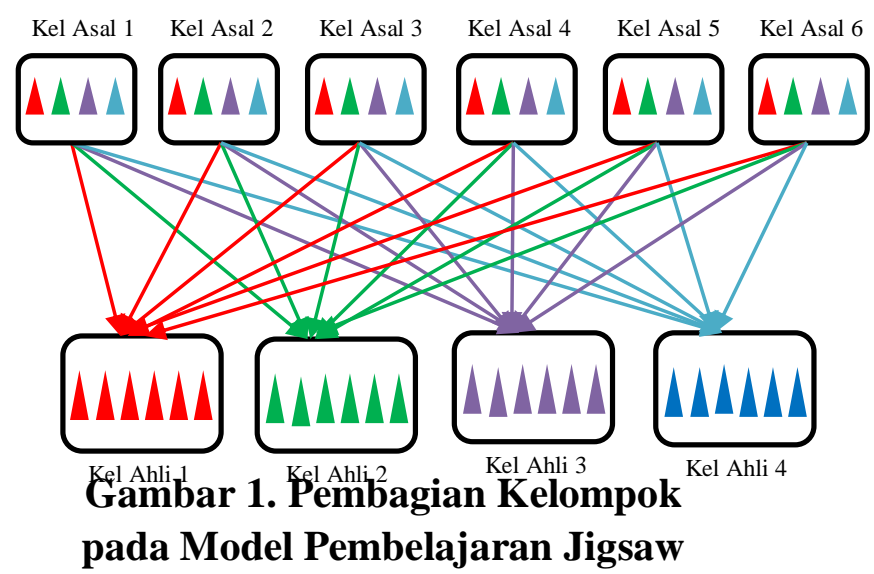

Hasil observasi terhadap hasil diskusikelompok ahi siklus 1 , tersaji pada tabel 2 berikut.

Tabel 2. Hasil Observasi diskusi Kelompok Ahli Siklus 1

\begin{tabular}{ccccc}
\hline Kel. Ahli & SA & A & KA & TA \\
\hline 1 & 3 & 2 & 0 & 1 \\
2 & 4 & 1 & 1 & 0 \\
3 & 1 & 3 & 2 & 0 \\
4 & 1 & 1 & 2 & 2 \\
\hline Ket: SA = Sangat Aktif, A = Aktif, \\
KA = Kurang Aktif, TA = Tidak \\
Aktif \\
Tugas anggota kelompok ahli
\end{tabular}


Vol II. No. 2, Maret 2018, hlm. 157 - 165

Available online at www.jurnal.una.ac.id/indeks/jmp

ketika kembali ke kelompok asal yakni menjelaskan materi yang telah dipelajari di kelompok ahli. Ketidakaktifan anggota ketika diskusi di kelompok ahli akan berdampak pada kurang maksimalnya penguasaan materi yang dibahas. Berdasarkan Tabel 1, tampak bahwa masih ada 3 mahasiswa yang tidak aktif berdiskusi di kelompok ahli. Selain itu belum semua mahasiswa yang membuat catatan ketika berdiskusi di kelompok ahli.

Siswa yang tidak aktif di kelompok ahli otomatis berdampak pada diskusi di kelompok asal. Hal ini terbuktipada hasil observasi diskusi di kelompok asal yang tersaji dalam Tabel 3 berikut.

Tabel3. Hasil Observasi diskusi Kelompok Asal Siklus 1

\begin{tabular}{ccccc}
\hline Kel. Asal & SA & A & KA & TA \\
\hline 1 & 2 & 1 & 1 & 0 \\
2 & 1 & 2 & 0 & 1 \\
3 & 0 & 1 & 1 & 2 \\
4 & 0 & 2 & 2 & 0 \\
5 & 1 & 0 & 1 & 2 \\
6 & 0 & 1 & 1 & 2 \\
\hline
\end{tabular}

Berdasarkan Tabel 3 tampak bahwa masih banyak mahasiswa yang tidak aktif saat diskusi di kelompok asal. Hal ini disebabkan ketika berdiskusi di kelompok ahli mereka tidak aktif, sehingga kurang menguasai materi yang akhirrnya berdampak pada anggota kelompok asal mereka juga tidak dapat memahami materi dengan baik

Hasil tes sebagai evaluasi di akhir siklus 1 tersaji pada tabel 4 berikut.
Tabel 4. Hasil Belajar Siswa Siklus

\begin{tabular}{ccc}
\multicolumn{3}{c}{$\mathbf{1}$} \\
\hline Kriteria & Jumlah & Presentase \\
\hline$<70$ & 10 & 41,67 \\
$\geq 70$ & 14 & 58,33 \\
\hline
\end{tabular}

Kurang efektifnya diskusi pada kelompok asal mempengaruhi capaian hasil belajar yang belum maksimal. Masih 58,33\% mahasiswa yang mendapat nilai $\geq 70$. Beberapa penyebab belum maksimalnya keefektifan dan hasil belajar pada siklus 1 antara lain karena: 1) mahasiswa membentuk kelompok masih berdasarkan pertemanan, sehingga heterogenitas belum tercapai; 2) jalannya diskusi pada kelompok ahli belum maksimal; 3) anggota kelompok ahli ada yang belum membuat catatan dengan baik sehingga berpengaruh pada tidak maksimalnya ahli dalam memandu diskusi di kelompok asal; 4) kerjasama saat diskusi di kelompok asal masih kurang, sehingga saat ada yang memandu diskusi kurang lancar, cenderung belum ada sumbangan yang signifikan dari anggota lainnya untuk memperdalam materi; 5) bantuan selama diskusi belum maksimal.

\section{Hasil Siklus 2}

Refleksi dari siklus 1 dapat digunakan untuk perencanaan siklus 2. Pemberian tindakan yang berbeda pada siklus 2 dilakukan supaya pembelajaran lebih efektif dan hasil belajar mahasiswa meningkat. Tindakan-tindakan yang dilakukan pada siklus 2 yaitu: 1) pembentukan kelompok asal yang homogen agar 
Vol II. No. 2, Maret 2018, hlm. 157 - 165

Available online at www.jurnal.una.ac.id/indeks/jmp

kelompok ahli menjadi heterogen; 2) meningkatkan frekuensi monitoring dosen pada kelompok ahli agar diskusi semakin optimal; 3) membuat aturan wajib membuat catatan bagi semua anggota kelompok ahli dan menjadikannya sebagai salah satu bentuk penilaian. Perencanaan pada siklus 2 dimaksimalkan dengan cara melakukan persiapan yang matang termasuk penyususnan RPP lebih diperjelas sehingga setiap kemungkinan yang terjadi saat pembelajaran dapat semaksimal mungkin diantisipasi. Ketika diskusi kelompok kurang lancar, dosen memonitor agar diskusi dapat berjalan lancar. Observasi tindakan pada siklus 2 menunjukkan bahwa pembelajaran berjalan lebih baik dari sebelumnya. Hasil observasi terhadap diskusi kelompok ahli disajikan sebagai berikut:

Tabel5. Hasil Observasi diskusi Kelompok Ahli Siklus 2

\begin{tabular}{ccccc}
\hline Kel. Ahli & SA & A & KA & TA \\
\hline 1 & 4 & 1 & 1 & 0 \\
2 & 2 & 3 & 1 & 0 \\
3 & 3 & 3 & 0 & 0 \\
4 & 1 & 2 & 2 & 1 \\
\hline
\end{tabular}

Ket: SA = Sangat Aktif, A = Aktif, $\mathrm{KA}=$ Kurang Aktif, TA $=$ Tidak Aktif

Berdasarkan tabel di atas tampak bahwa pelaksanaan diskusi pada kelompok ahli semakin baik. Hanya ada 1 mahasiswa yang tidak aktif. Untuk mahasiswa yang kurang aktif, berdasarkan hasil wawancara memberi informasi bahwa hal tersebut dikarenakan mereka kurang melakukan persiapan.
Diskusi kelompok asal juga memberikan hasil yang semakin baik. Berikut hasil observasi keaktifan mahasiswa saat diskusi kelompok asal pada siklus 2 .

Tabel 6. Hasil Observasi diskusi Kelompok Asal Siklus 2

\begin{tabular}{ccccc}
\hline Kel. Asal & SA & A & KA & TA \\
\hline 1 & 2 & 2 & 0 & 0 \\
2 & 1 & 2 & 1 & 0 \\
3 & 1 & 3 & 0 & 0 \\
4 & 3 & 1 & 0 & 0 \\
5 & 1 & 2 & 1 & 0 \\
6 & 2 & 1 & 1 & 0 \\
\hline
\end{tabular}

Karena diskusi di kelompok asal juga semakin baik, hal ini berdampak pada pencapaian hasil belajar yang juga semakin meningkat. Tabel 7 menunjukkan hasil belajar mahasiswa pada siklus 2 .

Tabel 7. Hasil Belajar Siswa Siklus

\begin{tabular}{ccc}
\multicolumn{3}{c}{$\mathbf{2}$} \\
\hline Kriteria & Jumlah & Presentase \\
\hline$<70$ & 4 & 16,67 \\
$\geq 70$ & 20 & 83,33 \\
\hline
\end{tabular}

\section{Pembahasan}

Persiapan dosen sebelum melaksanakan pembelajaran kooperatif tipe jigsaw sangat mempengaruhi keberhasilan strategistrategi yang diterapkan saat pembelajaran. Beberapa aspek yang dipersiapkan dengan lebih baik yakni: strategi pembentukan kelompok, strategi pemilihan materi, penjelasan jalannya pembelajaran model jigsaw pada mahasiswa, pemantauan kelompok, dan pendampingan kelompok saat diskusi. 
Vol II. No. 2, Maret 2018, hlm. 157 - 165

Available online at www.jurnal.una.ac.id/indeks/jmp

Pemahaman dosen pada karakteristik mahasiswa sangat berperan dalam proses pembelajaran (Jailani \& Hamid, 2016). Yang harus dipetakan dari pemahaman karakter atau kompetensi mahasiswa pada pembelajaran kooperatif tipe jigsaw antara lain: a) kemampuan membuat catatan, 2) kemampuan memimpin jalannya diskusi, 3) kemampuan verbal. Pada siklus 1, pembentukan kelompok yang diserahkan sepenuhnya kepada mahasiswa berdampak pada kurang optimalnya diskusi.

Pendalaman materi ketika diskusi di kelompok ahli merupakan salah satu kunci dari keberhasilan pembelajaran kooperatif tipe jigsaw. Oleh sebab itu, heterogenitas di kelompok ahli sangat penting agar diskusi dan pendalaman materi di kelompok ahli bisa maksimal. Agar terbentuk kelompok ahli yang heterogen, maka pembentukan kelompok asal harus benar-benar homogen. Dalam membentuk kelompok asal, karakteristik kompetensi mahasiswa perlu digunakan, karena ketika anggota kelompok asal membentuk kelompok ahli, karakter yang dibutuhkan untuk memperlancar diskusi dapat tercapai.

Kelompok asal dibentuk berdasarkan analisis karakteristik mahasiswa. Ketika kelompok asal homogen, maka akan terbentuk kelompok ahli yang heterogen. Diskusi di kelompok ahli pada siklus 2 menjadi lebih baik daripada siklus 1 . Di setiap kelompok ahli pasti ada anggota yang mempunyai kemampuan di atas rata-rata dalam penguasaan materi. Mahasiswa tersebut menjadi penggerak jalannya diskusi. Di setiap kelompok ahli juga ada anggota yang mempunyai kemampuan baik dalam membuat catatan hasil diskusi. Ketika diskusi sudah selesai, catatan masing-masing anggota kembali dibahas. mahasiswa yang baik dalam membuat catatan bisa membantu anggotanya untuk menyempurnakan catatan. Catatan tersebut akan digunakan masingmasing anggota sebagai bahan diskusi ketika kembali ke kelompok asal.

Pendampingan dosen pada siklus 1 belum maksimal karena peneliti bermaksud memberikan peran yang lebih kepada mahasiswa selama proses pembelajaran. Hasil observasi siklus 1 menunjukkan bahwa terdapat anggota kelompok ahli maupun kelompok asal yang belum bekerja dengan baik. Hal ini berdampak pada ketidaklancaran diskusi di kelompok asal. Perbaikan tindakan dilakukan pada siklus 2 yakni dengan memberikan pantauan dan pendampingan secara lebih intensif agar semua anggota kelompok aktif berdiskusi dan masing-masing anggota memberi dorongan kepada anggota lain untuk aktif.

Pada siklus 1 sumber belajar mahasiswa masih sangat terbatas. mahasiswa hanya mengandalkan 1 buku teks mata kuliah metode numerik. Selanjutnya dilakukan perbaikan pada siklus 2 dengan melakukan persiapan yang lebih matang. Pembentukan kelompok diumumkan pada mahasiswa 
Vol II. No. 2, Maret 2018, hlm. 157 - 165

Available online at www.jurnal.una.ac.id/indeks/jmp

beberapa hari sebelum pembelajaran dimulai. Masing-masing mahasiswa sudah mengetahui materi apa yang akan didiskusikan di kelompok ahli. Dampak perubahan dari persiapan ini adalah mahasiswa sudah mencari sumber belajar tambahan baik dari buku di perpustakaan, internet, maupun sumber lain.

Perbaikan tindakan pada siklus 2 berdampak pada keaktifan dan hasil belajar mahasiswa yang semakin meningkat, perbandingan keaktifan dan hasil belajar mahasiswa siklus 1 dan 2 tersaji pada tabel 8 dan tabel 9 berikut.

Tabel 8. Perbandingan Keaktifan Mahasiswa Siklus 1 dan Siklus 2

\begin{tabular}{ccccc}
\hline \multirow{2}{*}{$\begin{array}{c}\text { Krit } \\
\text { eria }\end{array}$} & \multicolumn{2}{c}{ Siklus 1 } & \multicolumn{2}{c}{ Siklus 2 } \\
Jum & $\begin{array}{c}\text { Perse } \\
\text { ntase }\end{array}$ & $\begin{array}{c}\text { Jum } \\
\text { lah }\end{array}$ & $\begin{array}{c}\text { Perse } \\
\text { ntase }\end{array}$ \\
\hline SA & 4 & 16,67 & 10 & 41,67 \\
A & 7 & 29,17 & 11 & 45,83 \\
KA & 6 & 25 & 3 & 12,5 \\
TA & 7 & 29,17 & 0 & 0 \\
\hline
\end{tabular}

Keaktifan siswa meningkat dari siklus 1 ke siklus 2, hal ini sejalan dengan hasil penelitian Miaz (2015) yang juga tentang penerapan pembelajaran kooperatif tipe jigsaw.

Table 9. perbandingan Hasil

Belajar Mahasiswa Siklus 1 dan Siklus 2

\begin{tabular}{ccccc}
\hline \multirow{2}{*}{$\begin{array}{c}\text { Krit } \\
\text { eria }\end{array}$} & \multicolumn{2}{c}{ Siklus 1 } & \multicolumn{2}{c}{ Siklus 2 } \\
& lah & $\begin{array}{c}\text { Perse } \\
\text { ntase }\end{array}$ & $\begin{array}{c}\text { Jum } \\
\text { lah }\end{array}$ & $\begin{array}{c}\text { Perse } \\
\text { ntase }\end{array}$ \\
\hline$<70$ & 10 & 41,67 & 4 & 16,67 \\
$\geq 70$ & 14 & 58,33 & 20 & 83,33 \\
\hline
\end{tabular}

Berdasarkan Tabel 9 di atas tampak bahwa pada siklus 2 hasil belajar mahasiswa meningkat dibanding siklus 1. Sehingga dapat dikatakan model pembelajaran kooperatif tipe jigsaw dapat meningkatkan hasil belajar mahasiswa. Hal ini sejalan dengan temuan yang diperoleh Widiastini, Kusmariyatni, \& Arini (2014) serta Liando (2014).

\section{SIMPULAN}

Penerapan pembelajaran kooperatif tipe jigsaw meskipun di tingkat universitas tetap memerlukan strategi dan persiapan yang maksimal. Strategi-strategi yang dilakukan antara lain: pemilihan materi yang cocok untuk model jigsaw, pembentukan kelompok asal yang homogen dengan tujuan terbentuk kelompok ahli yang heterogen, pemahaman karakteristik kompetensi mahasiswa, Pendampingan oleh dosen selama proses diskusi baik di kelompok asal maupun kelompok ahli, dan tambahan sumber belajar. Strategi penerapan pembelajaran kooperatif tipe jigsaw yang tepat dapat meningkatkan aktivitas dan hasil belajar mahasiswa.

Peneliti menyarankan agar para dosen mencoba menerapkan model pembelajaran kooperatif tipe jigsaw dalam perkuliahannya agar aktifitas mahasiswa dan hasil belajar meningkat. Namun sebelum menerapkan model ini perlu di buat persiapan strategi yang matang agar tujuan pembelajaran dapat tercapai dengan baik. Beberapa strategi yang ada pada hasil penelitian ini bisa 
Vol II. No. 2, Maret 2018, hlm. 157 - 165

Available online at www.jurnal.una.ac.id/indeks/jmp

dijadikan rujukan dalam membuat persiapannya.

\section{DAFTAR RUJUKAN}

Fathurrohman, M. (2015). Modelmodel pembelajaran inovatif. Yogyakarta: ARRUZZ Media.

Hudojo, Herman. (2005). Pengembangan Kurikulum dan Pembelajaran Matematika. Malang: UM PRESS.

Jailani, M. S., \& Hamid, A. (2016). Pengembangan Sumber Belajar Berbasis Karakter Peserta Didik (Ikhtiar optimalisasi Proses Pembelajaran Pendidikan Agama Islam (PAI)). Nadwa. JurnalPendidikan Islam Vol. 10, Nomor2, 175-192

Liando, M. R. (2014). Penerapan Model Pembelajaran Kooperatif Tipe Jigsaw untuk Meningkatkan Hasil Belajar. Jurnal Ilmiah Cisoc (KajianRumpun Pendidikan Ilmu Sosial)Volume 1 No. 01, 77 - 88.

Martinis, Yamin. (2013). Strategi danMetode dalam Model InovasiPembelajaran.

Jakarta: Gaung Persada Press Group.

Miaz, Y. (2015). Improving Students' Achievement of Social Science By Using Jigsaw Cooperative Learning Model at Primary School. IOSRJournal of Research \& Method inEducation Volume

5, Issue 4 Ver. II(Jul - Aug. 2015), 01-07

Rochiati, Wiriaatmadja. (2008). Metodepenelitian tindakan kelas untukmeningkatkan kinerja guru dandosen. Bandung: Remaja Rosdakarya.

Slavin, R. E. (2014). Instruction based on cooperative learning. Baltimore, Maryland, US: Johns Hopkins University.

Solihatin, E. \& Raharjo. (2008). Cooperative learning analisis modelpembelajaran ips. Jakarta: Bumi Aksara.

Widayanti, L., \& Hakim, L. 2017. Pembelajaran Kooperatif Tipe Jigsaw SebagaiUpaya Pendidikan Karakter Pada MatakuliahOperation

Research. Jurnal Matematika dan Pendidikan MatematikaVol. II No. 1 Maret.

Widiastini, M., Kusmariyatni, N., \& Arini, N. W. (2014). Keefektifan model pembelajaran kooperatif tipe jigsaw untuk meningkatkan hasil belajar IPS Siswa kelas V. JournalMimbar PGSD UniversitasPendidikan Ganesha JurusanPGSD Vol: 2 No: 1. 